\title{
Elements Explaining Learning Clinical Reasoning Using Simulation Games
}

\author{
Jaana-Maija Koivisto ${ }^{1}$, Elina Haavisto ${ }^{2}$, Hannele $\mathrm{Niemi}^{3}$, Jouko Katajisto ${ }^{4}$, Jari \\ Multisilta ${ }^{5}$ \\ 1,3 University of Helsinki \\ 1,3 \{jaana-maija.koivisto, hannele.niemi\}@helsinki.fi \\ 2 University of Turku, Hospital District of Satakunta \\ 2 elina.haavisto@utu.fi \\ ${ }^{4}$ University of Turku, jouko.katajisto@utu.fi \\ ${ }^{5}$ Tampere University of Technology, jari.multisilta@tut.fi
}

\begin{abstract}
This article presents the findings on which elements in a game-based simulation affect learning clinical reasoning in nursing education. By using engaging gaming elements in virtual simulations and integrating the clinical reasoning process into game mechanics, games can enhance learning clinical reasoning and offer meaningful learning experiences. The study was designed to explore how nursing students experience gaming and learning when playing a simulation game, as well as which gaming elements explain learning clinical reasoning. The data was collected by questionnaire from nursing students ( $N=166)$ in autumn 2014 over thirteen gaming sessions. The findings showed that usability, application of nursing knowledge, and exploration have the most impact on learning clinical reasoning when playing simulation games. Findings also revealed that authentic patient-related experiences, feedback, and reflection have an indirect effect on learning clinical reasoning. Based on these results, more efficient simulation games to improve clinical reasoning may be developed.
\end{abstract}

Keywords: clinical reasoning, learning, simulation games, nursing students

\section{Introduction}

Serious gaming is a valuable technology that improves learning and competence development in the healthcare sector by taking a student-oriented approach to education [1]. Serious games are used in health promotion [2], prevention [3], therapy [4], and rehabilitation [5]. One important use is professional training [6-9]. The majority of serious games used for educational purposes are simulations, with health disciplines being the most popular [10], and first aid being the field with the highest number of developed games [1]. Identifying high-risk patients, delivering safe and effective care, and preventing patient complications are prerequisites for ensuring patient safety and high quality patient care. Virtual scenarios provide a safe learning environment to practice patient care without harming real patients and learn from mistakes [11-12]. The use of medium and/or high fidelity simulation using manikins has been proven effective learning method for clinical learning [13] and their use has increased in last two decades. However, embedding serious games in nursing curriculum is insufficient. There is not much evidence on how students learn professional nursing through gaming or the effectiveness of games. Embedding game-based learning into curriculum requires nursing educators' knowledge and experience on how to evaluate games and their effectiveness. In recent years, frameworks for evaluating game-based learning and effectiveness of games have been developed to help educators to implement games in educational setting [14-15].

Simulation has a positive effect on student's knowledge acquisition, communication skills, selfconfidence, satisfaction and level of engagement in learning [16], and it increases student's knowledge and self-efficacy [17]. Interprofessional simulation increases confidence, knowledge, leadership, teamwork, and communication skills [18]. However, simulation delivered in classroom setting is 
expensive and time-consuming requiring space and personnel resources [19-20]. The benefit of gamebased simulation over classroom simulation is that it can be duplicated and distributed to an unlimited number of learners at any time and any place, and it permits repetition a number of times [11, 21]. In games, learners can proceed at their own pace and assess their own progress since the game tracks players' every action [21]. Cant and Cooper [6] found that most simulation-based nursing e-learning programs focus on the teaching of procedural skills, usually related to holistic patient care. However, there exists evidence that games can also be used to learn clinical reasoning (CR) [8-9, 22], which is one of the core competencies of professional nursing. Care of critically ill patients often involves complicated decisions undertaken rapidly in complex healthcare environments. Based on a recent study [23], game-based simulations are seen as an ideal space for experiential learning to occur. In welldesigned serious games, action-reflection cycles are written into the game mechanics. Squire [24] defines "designed experience" as one that emerges from a dialogue between the player's dynamic action and the context of the digital world in which they act. Gaming is an ongoing problem solving activity where the player identifies problems, sets goals to solve the problem, takes action, receives feedback, and reflects on that feedback [25]. CR can be seen as a problem-solving activity [26], and thus, designed experiences in games can provide an engaging learning environment for nursing students to begin developing expertise through simulated real-world practice [25]. Building the game mechanics around the CR process supports learning of CR by giving students a systematic approach to follow [8, 27]. However, not all nursing students benefit from games. Koivisto et al. [27] found that those nursing students that do not play digital games at all learned less than those who play daily or occasionally. However, it can be the other way around: previous gaming experience may have negative impact on learning, as game players are used to high levels of animations and graphics, interactivity, and fidelity that immerse them in the activity [28].

The purpose of the study was to describe and explain how nursing students learn CR by playing a simulation game. This study is part of a design-based research project that aims to create, implement, and redesign a 3D simulation game for nursing education. For present purposes, simulation games are defined as virtual scenarios delivered in web-based, mobile, or virtual reality learning environments that integrate gaming elements with learning objectives, in which learners simulate real-world situations and emulate the roles of healthcare professionals [23].

\section{Theoretical framework}

Nursing students are required to gain competence in CR [22, 30]. Lewett-Jones et al. [22] define CR as a "logical, dynamic and ongoing process by which nurses collect cues, process the information, come to an understanding of a patient's problem or situation, plan and implement interventions, evaluate outcomes, and reflect on and learn from the process". Koivisto et al. [23] applied the phases of LewettJones's CR cycle in their study, which investigated how nursing students learn clinical reasoning by playing games. According the findings of the study, learning CR by playing games consists of six phases: learn to collect information; process information; identify problems/issues; establish goals; take action; and evaluate outcomes [see 27]. In this study, the elements considered to be important for learning CR by playing games are: authentic patient-related experiences; active participation in patient care; application of nursing knowledge; exploration; feedback; reflection; collaborative gaming; and usability. These elements will be introduced by reflecting on the results of previous studies and are presented as the theoretical framework of the study (Figure 1).

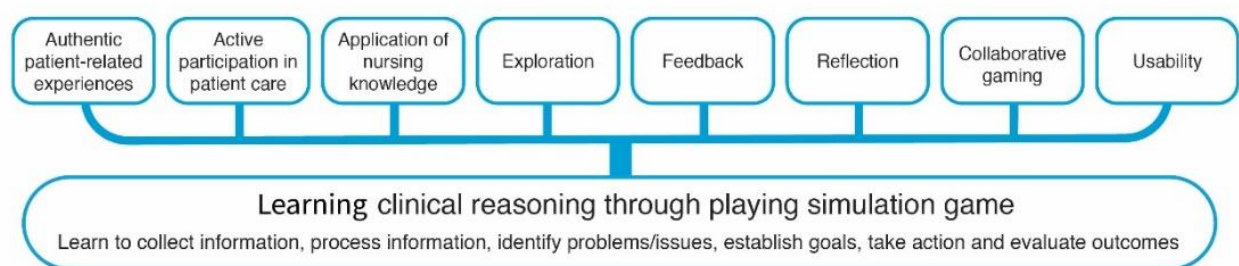

Figure 1. Theoretical framework of learning clinical reasoning through playing a simulation game 
Authentic patient-related experiences engage nursing students in CR activities through simulation games [23]. Authenticity and reliability of the patient scenarios helps support learning [9, 30-33]. Research shows that students' negative experiences with virtual simulations are connected to lack of authenticity and clinical realism in the scenarios [9, 34-35]. Koivisto et al. [23] found similar results in that realistic scenarios are important for learning, and their study also revealed that interaction between the player and the game is essential. Interaction is the essence of a clinical relationship, thus interaction enables realistic and engaging learning experiences.

Active participation in patient care during gaming prepares students to make the correct decision in CR situations [23]. Learning through games requires that learners can be active agents [36]. In virtual simulations, students become actively involved with the patient and the situation [30, 37]. Games provide opportunities for students to be active decision makers, including situations requiring quick decisions [23], and create opportunities for CR through acting and thinking while gaming [27]. McCallum et al. [38] found that students may not have the opportunity to make decisions in clinical placement, which could cause uncertainty about the skills required to make decisions in the future. They found that virtual simulation experiences provided students with the opportunity to practice decision-making, which gave them more confidence.

Application of nursing knowledge during gaming bridges the gap between theory and practice. Through games, nursing students can apply previously acquired theoretical and practical knowledge, as well as their experiences with patient care, in order to resolve patient scenarios [see 23, 39]. Simulation in general enables the application of knowledge and learning CR by putting theory into practice [22]. McCallum et al. [38] explored nursing students' decision-making through virtual scenario-based activity. They found that students made decisions based on theories they had learned and experiences they had gained from clinical practice. Nursing students have reported that virtual cases force them to consider what is important, and that they were able to apply their knowledge and skills [9].

Exploring while playing provides opportunities to improve performance. Exploration refers to attempting something, making mistakes and learning from them, and repeating this process during gameplay [see 23, 40-41]. Kidd et al. [42] found that students regarded a positive aspect of virtual simulations to be that they were able to make mistakes without consequences for real patients. Repetition helps nursing students to internalise and automate procedures, teaching them to prioritise by making their own decisions and seeing the concrete consequences, thus preparing students for real CR situations [23, 34]. Lewett-Jones et al. [43] found that simulation with manikins was a good way for students to demonstrate their CR skills, but virtual cases can also be used for assessing CR [9].

Feedback from performance is necessary in order for a student to benefit fully from their gaming experience. Feedback can be corrective, when learners are told if their answers are right or wrong, or explanatory, when the game provides the right and wrong answers together with explanations [see 44]. In any case, correction of errors during gameplay is associated with good learning outcomes [44-45]. Tsai et al. [46] studied how different feedback types affected the effectiveness of knowledge acquisition on game-based formative assessment in an online learning environment. They blended four types of feedback: immediate feedback (IF), delayed feedback (DF), knowledge of correct response (KCR), and elaborated feedback (EF). IF provides instant feedback to learners after completing an assessment or question. DF provides feedback messages after a few minutes or longer. KCR feedback offers the correct answer, whereas EF may or may not reveal the correct answer, but provides a detailed message that comprises information or clues relevant to the question, thus guiding learners toward the correct response. They concluded that providing immediate elaborated feedback promotes learning, and that different feedback types (IEF and non-IEF) significantly affect learning effectiveness. Erhel and Jamet [44] argue that digital learning games, accompanied by features such as feedback containing the correct responses, help students mobilize deep cognitive processes while learning. Goldberg and CannonBowers [47] also found that the inclusion of explicit feedback, regardless of the source, significantly improved performance in the training scenario. Nursing students favour immediate feedback on their performance [23, 48], and feel that the best feedback during gameplay is a change in the patient's clinical condition [23].

Reflection is critical for the development of clinical knowledge and improvement in CR [22, 26, 49]. According to Kuiper and Pesut [50], reflective CR in nursing practice depends on the development of both cognitive (critical thinking) and metacognitive (reflective thinking) skill acquisition. They argue that self-evaluation is a key factor in reflection, which influences critical thinking and the development of CR skills. Likewise, according to Bulman et al. [51], self-reflection is connected to professional development. Guiding and supporting the reflective process therefore promotes greater levels of reflectivity [50]. By embedding reflective activities in nursing simulation games [6], 
developers can provide opportunities for students to reflect on the results of their actions and performance both during and afterward [23, 26, 52]. While gaming, learners can reflect in action during the simulation and reflect on action after [53]. Tanner [26] defines reflection-in-action as nurses' ability to "read" the patient and plan interventions based on that assessment, and argues that much of this reflection-in-action is tacit and not obvious. Reflection-on-action, on the other hand, exposes what nurses gain from their experience and contributes to their ongoing development of clinical knowledge as well as their capacity for CR in the future [26]. Gaming provides students with opportunities to reflect on their learning through feedback, enabling learners to construct new mental models and discover new and better solutions to the problems encountered [54]. Georg and Zary [45] found that nursing students used immediate feedback for reflecting and identifying their knowledge and learning needs. Koivisto et al. [23] found similar results suggesting that the provision of reasoning for correct choices helps students to reflect both on decisions they have made and on their underlying knowledge. Feedback at the end of the game causes the players to consider and learn from their actions. The effects of the player's actions on the patient's clinical condition are important for seeing the consequences of said actions. Teixeira et al. [52] found that debriefing after a simulation allows students to reflect on the results of their actions and performance regarding patient care. It also made it possible to analyse mistakes that may be avoided in similar situations in the future, thus increasing patient safety.

Collaborative gaming enables students to reflect together on the patient scenarios and the clinical decisions they made while playing. Scenario-based simulation is good way to practise collaborative decision-making in education because it allows students to support one another's knowledge and skill acquisition [56]. Harmon and Thompson [57] studied whether collaborative activities were effective in improving nursing students' CR skills. They found that students processed information together using their shared theoretical knowledge, and that students' CR skills increased significantly with collaboration. In a study by Koivisto et al. [23], nursing students reported that they learned to make decisions in cooperation with other students even though the game was a single-player game. Rigby and Ryan [58] also state that players can find satisfaction through relatedness even in single-player games. Collaborative gaming offers opportunities for social relatedness and shared decision-making, which are important in patient care and may further enhance student learning [23].

Usability of a game has an impact on learning through gaming. Research shows that if gamers feel it is easy to become familiar with and get involved in a game, they will prefer it and increase their intention to continue using it [59]. Conversely, technical difficulties in virtual technologies may decrease their educational value [42]. Zhua et al. [59] adopted the technology acceptance model (TAM) to investigate factors affecting player acceptance of games. The technology acceptance model, developed by Davis, Bagozzi and Warshaw [60], has been used to explain whether users accept a new technology. Perceived usefulness is defined as the prospective user's subjective probability that using a specific application system will increase his or her job performance within an organizational context. Perceived ease of use refers to the degree to which the prospective user expects the target system to be free of effort. Zhua et al. [59] found that the perceived ease of use of online games had positive effects on perceived usefulness and user attitude, and perceived usefulness also had a positive effect on user attitude. They also found that user-perceived trust and attitude correlated positively with user intention of use. Heinrichs et al. [61] found that, in spite of participants experiencing technical difficulties during the virtual reality simulation, they thought it was useful for clinical skills training and team training. Fonseca et al. [48] evaluated 14 nursing students' perception on the serious game eBaby. They stated that the game could motivate students to learn. Students felt that the game was easy to use, and they perceived it useful because they could practice clinical assessment of preterm infants, apply their theoretical knowledge, and reflect on practice and the acquisition of new knowledge. In Georg and Zary's study [55] where they investigated nursing students' $(\mathrm{N}=50)$ perceived usefulness of the webbased Virtual Patients, formative feedback was given to students immediately after completing the encounter with the virtual patients. Students evaluated the perceived usefulness of the feedback at a medium level (out of medium, high, and very high level). Usefulness regarding learning CR was rated high.

\section{Purpose of the study}

The purpose of this study was to describe and explain how nursing students can learn clinical reasoning by playing a simulation game. The research questions were:

1. How do nursing students experience gaming and learning when playing a simulation game?

2. What elements explain learning clinical reasoning when playing a simulation game? 


\section{Method}

\subsection{Data collection}

In this research, purposive sampling was used to enable selection of certain subjects or events for inclusion in the study [62]. Data were collected during 13 gaming sessions from nursing students who participated in a surgical nursing course in autumn 2014 at two of Finland's largest universities of applied sciences. Permissions were obtained from the directors of the universities. The gaming session was one of the course's pedagogical solutions; in total, 166 undergraduate nursing students participated in these sessions. Participants were fully informed about the research at the beginning of the gaming session, both orally and with an information sheet. They were told that completion of the questionnaire was voluntary and that they could withdraw from the study at any time. They were asked to sign a form confirming their consent and participation.

More than half $(54.8 \%)$ of the participating students $(\mathrm{N}=166)$ were in the age group $21-25$, and the majority were in their second year of study. $60 \%$ of the participants had less than one year of work experience in the social and health services. In total, 63.2\% played digital games occasionally (weekly, about once a month, or less often). Participants played a Finnish version of the game, involving two to five postoperative patient scenarios. While some participants played the scenarios only once, most repeated the scenarios at least once. The gaming sessions were of 30-40-minute duration. After gameplay, all participants were asked to complete an online questionnaire. All information was processed confidentially.

The prototype of the CareMe simulation game used in this study is a single-player game developed at the University of Applied Sciences in Helsinki (Figure 2). The game was designed in collaboration with researchers, nurse educators, students, programmers, a 3D artist and an interface designer through iterative cycles of designing, testing, and refining the prototype [see 63-64]. In table 1, the learning and game mechanics of CareMe simulation game are presented by applying Arnab et al's [14] Learning Mechanics-Game Mechanics map. The Unity development platform was used to create the game. The game consists of patient scenarios, which are events designed around a specific clinical situation requiring clinical reasoning. The game mechanics are built around the clinical reasoning process. In the game, the player takes the role of nurse. The game view includes a 3D character (the patient) in a $3 \mathrm{D}$ environment representing hospital ward, with authentic reactions and equipment. The game is immersive in that it focuses on genuine patient concerns and the willingness of the player to help the patient. The system provides for immediate, sustained, and cumulative feedback in the form of reasoning, points, patient reactions, in-game facilitator's comments, and success and failure effects. The game also has a fast-paced complication mode, in which players compete against time and must make quick decisions.

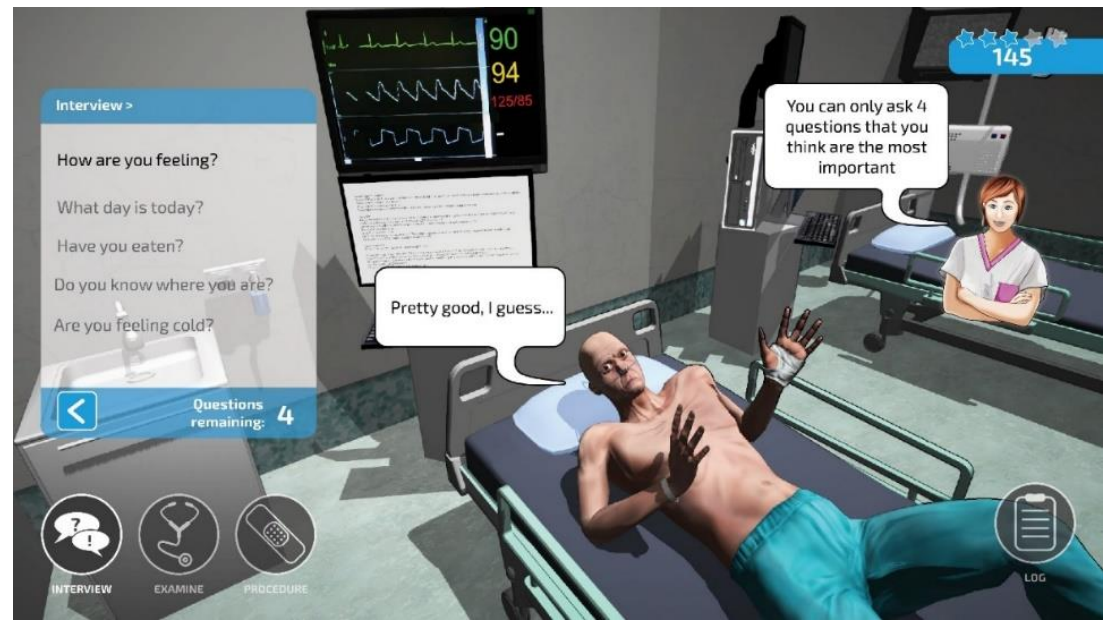

Figure 2. Screenshot from the simulation game 
Table 1. Learning and game mechanics in CareMe simulation game

\begin{tabular}{c|c}
\hline $\begin{array}{c}\text { Learning } \\
\text { mechanics }\end{array}$ & Game mechanics \\
\hline Simulation & Realism \\
\hline Instructional & Role play \\
\hline Guidance & Simulate/Response \\
\hline Observation & Strategy/Planning \\
\hline Participation & Question \& Answer \\
\hline Question \& Answer & Levels \\
\hline Identify & Time pressure \\
\hline Plan & Metagame \\
\hline Experimentation & Rewards/Penalties \\
\hline Action/Task & Assessment \\
\hline Assessment & Feedback \\
\hline Feedback & Action Points \\
\hline Reflect & \\
\hline Analyse & \\
\hline Repetition & \\
\hline Responsibility &
\end{tabular}

\subsection{Instrument}

As no instrument that measures learning clinical reasoning through playing a simulation game was available, an instrument was purposefully developed for this ongoing research project. The instrument was developed based on the theoretical framework of this study (Figure 1.). Subscales and items are presented in Appendix 1. Subscale 1, learning clinical reasoning through gaming, consists of six phases of the clinical reasoning process: learn to collect information, process information, identify problems/issues, establish goals, take action, and evaluate outcomes. Descriptive results from students' experiences of learning clinical reasoning through gaming are presented elsewhere [see 27]. Subscales 2 authentic patient-related experiences; 3 active participation in patient care; 4 application of nursing knowledge; 5 exploration; 6 feedback; 7 reflection; 8 collaborative gaming; and 9 usability are the eight important elements for successfully learning clinical reasoning through gaming. Participants evaluated the game and learning with a four-point Likert scale (definitely agree-definitely disagree). The instrument was pilot-tested with five nursing students. Some changes were made to the items, measurement scales, and instructions to respondents.

\subsection{Statistical Analysis}

Data analysis was performed using the statistical program SPSS 22.0. Descriptive statistics and frequency tables were used to characterize variables. Sum variables were formed according to theoretical categories. These were obtained by adding up the coded answers and dividing the calculated sum by the number of variables. Therefore, the sum variables have the same scale as individual items. The sum variables' reliability was evaluated by calculating Cronbach's alpha coefficients, and by examining the compatibility of single questions with the instrument through item analysis. Dependencies between sum variables were examined with Pearson correlation coefficients. The stepwise linear regression model was used to discover statistically significant predictors for learning clinical reasoning through gaming. Observed significance levels of $<0.05$ were considered to be statistically significant. Exact p-values are reported in text. 


\section{Results}

\subsection{Nursing students' experiences of gaming and learning when playing a simulation game}

Of the above subscales, students reported that subscale 5, exploration, rated best $(\mathrm{M}=3.52, \mathrm{SD}=0.492)$ and subscale 8 , collaborative gaming, rated least $(\mathrm{M}=2.94, \mathrm{SD}=0.837)$ (Table 2). For single items, item 5.3 "I can make mistakes safely in the game" had the highest mean value $(\mathrm{M}=3.7, \mathrm{SD}=0.558)$. Item 2.5 "Patient interaction felt real" had the lowest mean value $(\mathrm{M}=2.33, \mathrm{SD}=0.91)$. For item 7.4 "While playing I considered decisions together with other students", the answers varied (SD = 1.037).

Table 2. Nursing students' experiences of the game and learning when playing a simulation game $(\mathrm{N}=163-166)$

\begin{tabular}{l|l|l|l}
\hline Subscales & Mean & $\begin{array}{l}\text { Standard } \\
\text { deviation }\end{array}$ & $\begin{array}{l}\text { Cronbach's } \\
\text { alpha }\end{array}$ \\
\hline $\begin{array}{l}\text { 1. Learning clinical reasoning through gaming }(6 \\
\text { items)* }\end{array}$ & 3.08 & 0.713 & 0.922 \\
\hline $\begin{array}{l}\text { 2. Authentic patient-related experiences (5 items) } \\
\text { 3. Active participation in patient care (1 item) }\end{array}$ & 3.0 & 0.509 & 0.718 \\
\hline 4. Application of nursing knowledge (3 items) & 3.25 & 0.633 & 0.751 \\
\hline 5. Exploration (4 items) & 3.52 & 0.492 & 0.753 \\
\hline 6. Feedback (8 items) & 3.1 & 0.549 & 0.851 \\
\hline 7. Reflection (5 items) & 2.99 & 0.573 & 0.682 \\
\hline 8. Collaborative gaming (2 items) & 2.94 & 0.837 & 0.759 \\
\hline 9. Usability (7 items) & 3.09 & 0.606 & 0.873 \\
\hline
\end{tabular}

*Scale: 5 = very much, 4 = quite a lot, 3 = moderately, $2=$ somewhat, $1=$ not at all

Scale: 4 = definitely agree, 3 = somewhat agree, 2 = somewhat disagree, $1=$ definitely disagree

\subsection{Elements explaining learning clinical reasoning through playing a simulation game}

The elements of learning clinical reasoning through playing a simulation game showed strong positive correlations with each other (Table 3). Dependence between the elements was statistically significant. The strongest correlation was between subscale 4, application of nursing knowledge, and subscale 9 usability $(\mathrm{r}=0.757)$. The weakest correlation was between subscale 8 , collaborative gaming, and subscale 3 , active participation in patient care $(\mathrm{r}=0.220)$. 
Table 3. Correlations between the elements of learning clinical reasoning through playing

\begin{tabular}{|c|c|c|c|c|c|c|c|c|c|}
\hline & $\begin{array}{l}1 . \\
\text { Learning } \\
\text { clinical } \\
\text { reason- } \\
\text { ing } \\
\text { through } \\
\text { gaming }\end{array}$ & $\begin{array}{l}2 . \\
\text { Authen- } \\
\text { tic } \\
\text { patient } \\
\text { related } \\
\text { experi- } \\
\text { ences }\end{array}$ & $\begin{array}{l}3 . \\
\text { Active } \\
\text { particip } \\
\text { ation in } \\
\text { patient } \\
\text { care }\end{array}$ & $\begin{array}{l}4 . \\
\text { Applica } \\
\text { tion of } \\
\text { nursing } \\
\text { know- } \\
\text { ledge }\end{array}$ & $\begin{array}{l}5 . \\
\text { Explor } \\
\text { ation }\end{array}$ & $\begin{array}{l}6 . \\
\text { Feed- } \\
\text { back }\end{array}$ & $\begin{array}{l}7 . \\
\text { Reflec- } \\
\text { tion }\end{array}$ & $\begin{array}{l}8 . \\
\text { Colla- } \\
\text { borative } \\
\text { gaming }\end{array}$ & $\begin{array}{l}9 . \\
\text { Usability }\end{array}$ \\
\hline $\begin{array}{l}1 . \\
\text { Learning } \\
\text { clinical } \\
\text { reasoning } \\
\text { through } \\
\text { gaming }\end{array}$ & 1 & 0.497 & 0.328 & 0.594 & 0.387 & 0.481 & 0.569 & 0.379 & 0.622 \\
\hline $\begin{array}{l}2 . \\
\text { Authentic } \\
\text { patient } \\
\text { related } \\
\text { experience } \\
\text { s }\end{array}$ & & 1 & 0.451 & 0.616 & 0.519 & 0.538 & 0.541 & 0.337 & 0.615 \\
\hline $\begin{array}{l}3 . \\
\text { Active } \\
\text { participati } \\
\text { on in } \\
\text { patient } \\
\text { care }\end{array}$ & & & 1 & 0.449 & 0.325 & 0.380 & 0.381 & 0.220 & 0.376 \\
\hline $\begin{array}{l}4 . \\
\text { Applicatio } \\
\text { n of } \\
\text { nursing } \\
\text { knowledge }\end{array}$ & & & & 1 & 0.611 & 0.612 & 0.714 & 0.448 & 0.757 \\
\hline $\begin{array}{l}5 . \\
\text { Explorat- } \\
\text { ion }\end{array}$ & & & & & 1 & 0.469 & 0.522 & 0.369 & 0.711 \\
\hline $\begin{array}{l}6 . \\
\text { Feedback }\end{array}$ & & & & & & 1 & 0.527 & 0.313 & 0.580 \\
\hline $\begin{array}{l}7 . \\
\text { Reflection }\end{array}$ & & & & & & & 1 & 0.701 & 0.699 \\
\hline $\begin{array}{l}8 . \\
\text { Collaborati } \\
\text { ve gaming }\end{array}$ & & & & & & & & 1 & 0.499 \\
\hline $\begin{array}{l}9 . \\
\text { Usability }\end{array}$ & & & & & & & & & 1 \\
\hline
\end{tabular}

At this point, the stepwise regression model was used to determine what factors explain learning clinical reasoning through gaming. Three predictors were significant in the stepwise regression model. The selected regression model predicted elements of learning CR by gaming effectively $\left(R^{2}=.49\right.$, $F(3,157)=50.925, p<.001)$ (Table 4). Subscales 9 usability, 4 application of nursing knowledge, and 5 exploration had a positive and significant relationship with learning clinical reasoning through gaming. Subscale 9 usability was the most important factor explaining learning clinical reasoning through gaming. A second important factor was subscale 4, application of nursing knowledge, while the weakest was subscale 5 exploration.

Subscales 2 authentic patient related experiences, 6 feedback, and 7 reflection had an indirect effect on learning CR through gaming. Subscale 9 usability had strong positive correlation $(\mathrm{r}>0.7)$ with subscales 4 application of nursing knowledge $(\mathrm{r}=0.757)$, and 5 exploration $(\mathrm{r}=0.711)$. In 
addition, it had moderate positive correlation ( $\mathrm{r}>0.5)$ with subscales 2 authentic patient related experiences $(\mathrm{r}=0.615), 6$ feedback $(\mathrm{r}=0.580)$, and 7 reflection $(\mathrm{r}=0.699)$. Subscale 4 application of nursing knowledge had strong positive correlation with subscales 7 reflection $(\mathrm{r}=0.714)$ and 9 usability. It had moderate positive correlation with subscales 2 authentic patient related experiences ( $\mathrm{r}$ $=0.616), 5$ exploration $(\mathrm{r}=0.611)$, and 6 feedback $(\mathrm{r}=0.612)$. Subscale 5 exploration had strong positive correlation with subscale 9 usability, and moderate positive correlation with subscales 2 authentic patient related experiences $(\mathrm{r}=0.519), 4$ application of nursing knowledge, and 7 reflection $(r=0.522)$. The findings of this study are summarized in Figure 3. The figure presents the explaining factors for learning clinical reasoning through gaming, and those elements that have a strong or moderate correlation with the explanations.

Table 4. Regression model for elements explaining learning clinical reasoning through playing a simulation game

\begin{tabular}{l|l|l|l|l|l}
\hline Predictor & $B$ weight & SE $B$ weight & SRC & $T$ & Sig. $T$ \\
\hline Usability & 0.718 & 0.116 & 0.611 & 6.174 & $<0.001$ \\
Application of nursing knowledge & 0.332 & 0.108 & .270 & 3.063 & 0.003 \\
Exploration & -0.299 & 0.119 & -.205 & $-2,510$ & 0.013 \\
\hline
\end{tabular}

$\mathrm{R}=0.70 ; \mathrm{R}$-squared $=0.49 ; \mathrm{F}=50.925 ; \mathrm{df}=3,157, \mathrm{p}<.001$

Note: $\mathrm{SE}=$ standard error; $\mathrm{SRC}=$ standardised regression coefficient $($ Beta $) ; \mathrm{T}=\mathrm{t}$-test value.

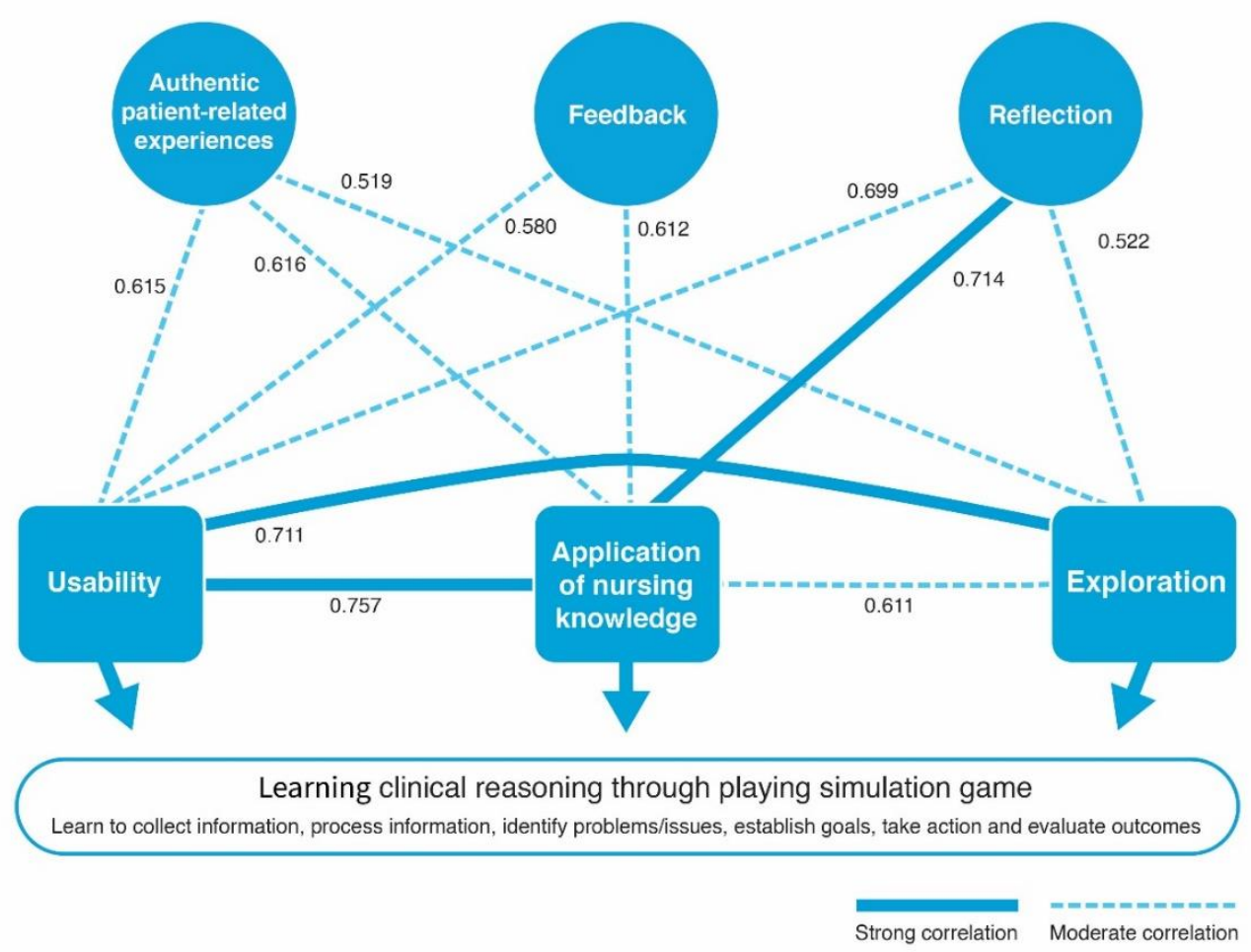

Figure 3. Summary of findings of learning clinical reasoning through playing a simulation game

\section{Discussion}

The purpose of the study was to describe and explain how nursing students learn clinical reasoning by playing a simulation game. The findings showed that usability, application of nursing knowledge and exploration have the most impact on learning clinical reasoning when playing simulation games. Based 
on the present findings, usability is the most important factor in learning clinical reasoning. The results confirm Fonseca et al. [48] and Zhua et al.'s [59] findings that the usability of the game has an impact on its educational value. When developing digital games for learning it is necessary to pay attention to ease of use and intuitiveness of the user interface. Nevertheless, great importance is also how useful students perceive the game in terms of learning. Combining theoretical knowledge with practice is one of the major advantages of simulations. Based on the present findings, application of nursing knowledge is strongly connected with learning clinical reasoning. This aligns with the findings of previous studies [see 9, 23, 38-39], where nursing students learned to make decisions by applying previously acquired theoretical and practical knowledge in virtual scenarios. The results also show that exploring while playing games has an effect on learning clinical reasoning. This aligns with previous studies, whose findings show that the opportunity to make mistakes and learn from them without consequences for real patients is an important factor for student learning [23, 40-42). These results indicate that students were able to test their competence using the game, which confirms Forsberg et al.'s [9] findings that virtual cases can be used for assessment of clinical reasoning skills.

Findings revealed that authentic patient-related experiences, feedback, and reflection have an indirect effect on learning clinical reasoning. They did not explain learning but they have strong influence in background and thus are important elements in simulation games for learning clinical reasoning. Authentic patient-related experiences and learning clinical reasoning have a positive relationship. This echoes the findings of previous studies, which have stated that the authenticity and clinical realism of virtual simulations support student learning [9, 30-33]. If patient scenarios are not realistic and virtual patients lifelike, immersion can be diminished which in turn can reduce learning. The results also confirm Guise et al. [30] and Heinrich et al.'s [37] findings that students are able to become actively involved with the patient in virtual scenarios. However, the results of this study revealed only weak correlation with learning clinical reasoning, and it did not explain student learning. This may be due to the fact that in a game, the interaction between a virtual patient and the player may not feel as real as with patients in live situations. This aligns with the results of Koivisto et al. [23], which stated that interaction with the virtual patient and the player in simulation games is important for creating realistic clinical situations where immersion can be reached.

Previous studies [23, 44-47] have found that feedback during and after gaming is connected with successful learning. These results indicate that receiving immediate feedback on decisions, correction of mistakes during gaming, continuous feedback on performance, and feedback after a completed scenario made students consider their decisions, enabled them to follow competency development, and revealed their understanding. Based on the present findings, feedback has a moderately strong relationship with the application of nursing knowledge and usability, which in turn explains learning clinical reasoning through gaming. While playing students apply their theoretical knowledge and getting feedback during gaming reveals their competence. Getting feedback is a key factor influencing on how useful the game is for learning.

Tanner [26] states that reflection-in-action refers to nurses' ability to "read" the patient. To be able to do that in real situations, students need both theoretical knowledge and experience with patient care. According to the present findings, reflection has a strong relationship with the application of nursing knowledge. These results indicate that in the game, students consider different options and make their decisions using their experiences with patient care. This self-reflection is connected to professional development [51]. Based on the present findings, $41 \%$ of the students responded that their professionalism evolved through gaming. In the present findings, reflection also has a strong relationship with collaborative gaming. The results confirm Koivisto et al.'s [23] findings, whereby nursing students learn to make decisions on patient care in cooperation with other students even when the game they played is a single-player game, if the learning situation enables discussion. While gaming, students can consider decisions together and learn from each other. This prepares them for real situations, where decisions will be made in collaboration with different professionals participating in patient care in a clinical setting. According to Kuiper and Pesut [50], reflective clinical reasoning depends on the development of critical and reflective thinking. These results show that simulation games can be used for developing critical and reflective thinking, as they provide opportunities for applying knowledge, making decisions, getting feedback and reflecting during gaming [see 24].

In summary, application of nursing knowledge and exploration are important factors in learning clinical reasoning through playing a simulation game. An interesting question for future research would be that if those elements do not realise or realise weakly during gaming, what kind of effect does it have on the elements that have an indirect effect on learning clinical reasoning. Conversely, if authentic patient-related experiences, feedback and reflection realises weakly, how does it influence on predictors of learning. 


\subsection{Validity and reliability}

As the instrument was developed for this study and was used here for the first time, this may reduce the validity of the findings. The instrument was pilot tested by nursing students. Two senior lecturers holding doctoral degrees in nursing science and one senior lecturer with experience of using games in nursing education evaluated the instrument to ensure its content and construct validity. Some changes were made to variables, measurement scales, and instructions to respondents. Students answered the questionnaire immediately after gaming; this positively affected the number of responses, as all participants responded. The internal consistency of the instrument was good (Cronbach's alpha 0.682 - 0.922). Based on Cronbach's alpha, it can be concluded that the subscales were reliable.

Generalisation of the results may be undermined by the fact that data were collected by using nursing students' self-report questionnaire and collected from only two universities. In addition, the game prototype used in this study was still in development phase and its validity had not been systematically evaluated. However, the results of this study gave important information for developing the game further. To improve the validity of the results, quasi-experimental design with pre- and posttest could be used for evaluating nursing students' learning clinical reasoning through gaming. In addition, the simulation game used in this study should be systemically validated. To improve the reliability of these results, the study should be repeated with a larger sample size or by comparing different simulation games.

\section{Conclusion}

The main conclusion of this study is that simulation games can enhance learning, as nursing students positively evaluated the simulation game and their learning of clinical reasoning through gaming. Usability, application of nursing knowledge, and exploration have the most impact on learning clinical reasoning when playing simulation games; in addition, authentic patient-related experiences, feedback, and reflection are important factors connected to learning clinical reasoning. These factors should be taken into consideration when using games in nursing education and when deciding what kind of games are suitable for learning clinical reasoning. These factors should also be given great importance when designing future simulation games for nursing education. Since simulation games have significance in terms of learning, they can be strongly recommended to be embedded into nursing curricula.

\section{Acknowledgements}

The authors would like to thank Anna-Saida Koskiluoma, Tuomas Louhelainen and Saku Nylund for their contribution to the development of the CareMe simulation game.

\section{References}

[1] Ricciardi, F., \& De Paolis, L.T. (2014). A comprehensive review of serious games in health professions. International Journal of Computer Games Technology, 9. Article ID 787968. https://doi.org/10.1155/2014/787968

[2] Sturm, J., Margry, S., van Doorn, M., \& Sluis-Thiescheffe, W. (2014). Meaningful feedback at opportune moments: How persuasive feedback motivates teenagers to move. Games for Health. Proceedings of the 4th conference on gaming and playful interaction in healthcare, 136-139. https://doi.org/10.1007/978-3-658-07141-7_18

[3] Falco, M., Schell, J., \& Witan, D. (2014). Tunnel Tail: A New Approach to Prevention. Games for Health. Proceedings of the 4th conference on gaming and playful interaction in healthcare, 27-36. https://doi.org/10.1007/978-3-658-07141-7_5

[4] Deen, M., Heynen, E. J. E., Schouten, B. A. M., van der Helm, P. G. H. P., \& Korebrits, A. M. (2014). Games [4Therapy] Project: Let's talk! Games for health. Proceedings of the 4th conference on gaming and playful interaction in healthcare, 15-26. 
[5] Burke, J. W., McNeill, M. D. J., Charles, D. K., Morrow, P. J., Crosbie, J. H., \& McDonough, S. M. (2009). Optimising engagement for stroke rehabilitation using serious games. Visual Computer (2009) 25: 1085-1099. https://doi.org/10.1007/s00371-009-0387-4

[6] Cant, R. P., Cooper, S. J. (2014). Simulation in the internet age: The place of web-based simulation in nursing education. An integrative review. Nurse Education Today 34, 1435-1442. https://doi.org/10.1016/j.nedt.2014.08.001

[7] Graafland, M., Schraagen, J. M., \& Schijven, M. P. (2012). Systematic review of serious games for medical education and surgical skills training. British Journal of Surgery 99, 1322-1330. https://doi.org/10.1002/bjs.8819

[8] Petit Dit Dariel O. J., Raby T., Ravaut F., \& Rothan-Tondeur M. (2013). Developing the serious games potential in nursing education. Nurse Education Today 33(12), 1569-1575. https://doi.org/10.1016/j.nedt.2012.12.014

[9] Forsberg, E., Georg, C., Ziegert, K., \& Fors, U. (2011). Virtual patients for assessment of clinical reasoning in nursing: A pilot study. Nurse Education Today 31, 757-762. https://doi.org/10.1016/j.nedt.2010.11.015

[10] Connolly, T. M., Boyle, E. A., MacArthur, E., Hainey, T., \& Boyle, J. M. (2012). A systematic literature review of empirical evidence on computer games and serious games. Computers \& Education 59, 661-686. https://doi.org/10.1016/j.compedu.2012.03.004

[11] Zary, N., Johnson, G., Boberg, J. \& Fors, U. (2006). Development, implementation and pilot evaluation of a Web-Based Virtual Patient Case Simulation environment - Web-SP. BMC Medical Education 6(10). https://doi.org/10.1186/1472-6920-6-10

[12] Dev, P., Heinrichs, LR. \& Youngblood, P.Y. (2011). CliniSpace: a multiperson 3D online immersive training environment accessible through a browser. Stud Health Technol Inform 163:173-9.

[13] Cant, R.P. \& Cooper, S.J. (2010). Simulation-based learning in nurse education: systematic review. Journal of Advanced Nursing, 66(1), 3-15. https://doi.org/10.1111/j.1365-2648.2009.05240.x

[14] Arnab, S., Lim, T., Carvalho, M.B., Bellotti, F., de Freitas, S., Louchart, S., Suttie, N., Berta, R. \& De Gloria, A. (2015). Mapping learning and game mechanics for serious games analysis. British Journal of Educational Technology Vol 46(2), 391-411. https://doi.org/10.1111/bjet.12113

[15] de Freitas, S. \& Oliver, M. (2006). How can exploratory learning with games and simulations within the curriculum be most effectively evaluated? Computers \& Education 46, 249-264. https://doi.org/10.1016/j.compedu.2005.11.007

[16] Gillan, P., Jeong, S. \& van der Riet, P. (2014). End life care simulation: A review of the literature. Nurse Education Today 34, 766-774. https://doi.org/10.1016/j.nedt.2013.10.005

[17] Akhu-Zaheya, L.M., Gharaibeh, M.K. \& Alostaz Z.M. (2013). Effectiveness of simulation knowledge acquisition, knowledge retention and self-efficacy of nursing students in Jordania. Clinical Simulation In Nursing 9, e335-e342. https://doi.org/10.1016/j.ecns.2012.05.001

[18] Gough, S., Hellaby, M., Jones, N. \& MacKinnon, R. (2012). A review of undergraduate interprofessional simulation-based education (IPSE). Collegian 19, 153-170. https://doi.org/10.1016/j.colegn.2012.04.004

[19] Zigmont, J. J., Kappus, L. J. \& Sudikoff, S. N. (2011). Theoretical foundations of learning through simulation. Seminars in Perinatology, 35, 47-51. https://doi.org/10.1053/j.semperi.2011.01.002

[20] Alinier, G. (2011). Developing high-fidelity health care simulation scenarios: A guide for educators and professionals. Simulation Gaming, 42(1), 9-26. https://doi.org/10.1177/1046878109355683

[21] Taekman, J.M. \& Shelley, K. (2010). Virtual environments in Healthcare: Immersion, Distripution, and flow. International Anesthesiology Clinics, 48(3), 101-121. https://doi.org/10.1097/AIA.0b013e3181eace73

[22] Lewett-Jones, T., Hoffman, K., Dempsey, J., Yeun-Sim Jeong, S., Noble, D., Norton, C. A., Roche, J., \& Hickey, N. (2010). The 'five rights' of clinical reasoning: An educational model to enhance nursing students' ability to identify and manage clinically 'at risk' patients. Nurse Education Today 30(6), 515-520. https://doi.org/10.1016/j.nedt.2009.10.020

[23] Koivisto, J.-M., Niemi, H., Multisilta, J. \& Eriksson, E. (2015). Nursing students' experiential learning processes using an online 3D simulation game. Education and Information Technologies. https://doi.org/10.1007/s10639-015-9453-X

[24] Squire, K. (2006). From Content to Context: Videogames as Designed Experience. Educational Researcher 35(8), 19-29. https://doi.org/10.3102/0013189X035008019

[25] Bauman, E. B. (2012). Game-Based Teaching and Simulation in Nursing and Healthcare. New York, NY, USA: Springer Publishing Company. ProQuest ebrary. Accessed 15 August 2015. 
[26] Tanner, C. A. (2006). Thinking Like a Nurse: A Research-Based Model of Clinical Judgment in Nursing. Journal of Nursing Education 45(6), 204-211.

[27] Koivisto, J-M., Multisilta, J., Niemi, H., Katajisto, J. \& Eriksson, E. (2016). Learning by playing: A cross-sectional descriptive study of nursing students' experiences of learning clinical reasoning. Nurse Education Today 45, 22-28. https://doi.org/10.1016/j.nedt.2016.06.009

[28] de Freitas, S., Rebolledo-Mendez, G., Liarokapis, F., Magoulas, G. \& Poulovassilis, A. (2010). Learning as immersive experiences: Using the four-dimensional framework for designing and evaluating immersive learning experiences in a virtual world. British Journal of Educational Technology Vol 41(1), 69-85. https://doi.org/10.1111/j.1467-8535.2009.01024.x

[29] Kajander-Unkuri, S., Salminen, L., Saarikoski, M., Suhonen, R., \& Leino-Kilpi, H. (2013). Competence areas of nursing students in Europe. Nurse Education Today 33, 625 - 632. https://doi.org/10.1016/j.nedt.2013.01.017

[30] Guise, V., Chambers, M., Conradi, E., Kavia, S., \& Välimäki, M. (2012). Development, implementation and initial evaluation of narrative virtual patients for use in vocational mental health nurse training. Nurse Education Today 32, 683-689. https://doi.org/10.1016/j.nedt.2011.09.004

[31] Honey, M., Connor, K., Veltman, M., Bodily, D., \& Diener, S. (2012). Teaching with Second Life: Hemorrhage Management as an Example of a Process for Developing Simulations for Multiuser Virtual Environments. Clinical Simulation in Nursing 8, e79 - e85. https://doi.org/10.1016/j.ecns.2010.07.003

[32] LeFlore, J-L., Anderson, M., Zielke, M. A., Nelson, K. A., Thomas, P. E., Hardee, G., \& John, L. D. (2012). Can a virtual patient trainer teach student nurses how to save lives: Teaching nursing students about pediatric respiratory diseases. Simulation in Healthcare Simulations: The Journal of the Society for Medical Simulation 7(1), 10-17. https://doi.org/10.1097/SIH.0b013e31823652de

[33] Rizzo, A.S., Kenny, P., \& Parsons, T.D. (2011). Intelligent virtual patients for training clinical skills. Journal of Virtual Reality and Broadcasting 8(3). doi:10.20385/1860-2037/8.2011.3

[34] Roh, Y. S., Lee, W. S., Chung, H. S., \& Park, Y. M. (2013). The effects of simulation-based resuscitation training on nurses' self-efficacy and satisfaction. Nurse Education Today 33, 123128. https://doi.org/10.1016/j.nedt.2011.11.008

[35] Hurst, H.M., \& Marks-Maran, D. (2011). Using a virtual patient activity to teach nurse prescribing. Nurse Education in Practice 11(3), 192-198. https://doi.org/10.1016/j.nepr.2010.08.008

[36] Gee, J.P. (2005). Learning by Design: good video games as learning machines. E-Learning and Digital Media 2(1), 5-16. https://doi.org/10.2304/elea.2005.2.1.5

[37] Heinrichs, C., Pennington, R.R., \& Kuiper, R. (2012). Virtual case studies in the classroom improve student knowledge. Clinical Simulation in Nursing 8(8), 353-361. https://doi.org/10.1016/j.ecns.2011.02.002

[38] McCallum, J., Ness, V., \& Price, T. (2011). Exploring nursing students' decision-making skills whilst in a Second Life simulation laboratory. Nurse Education Today 31, 699-704. https://doi.org/10.1016/j.nedt.2010.03.010

[39] Blakely, G., Skirton, H., Cooper, S., Allum, P., \& Nelmes, P. (2009). Educational gaming in the health sciences: a systematic review. Journal of Advanced Nursing 65(2), 259-269. https://doi.org/10.1111/j.1365-2648.2008.04843.X

[40] Heinrichs, W. L. R., Youngblood, P., Harter, P. M., \& Dev, P. (2008). Simulation for team training and assessment: Case studies of online training with virtual worlds. World Journal of Surgery 32(2), 161-170. https://doi.org/10.1007/s00268-007-9354-2

[41] Foronda, C., Gattamorta, K., Snowden, K., \& Bauman, E. B. (2014). Use of virtual clinical simulation to improve communication skills of baccalaureate nursing students: A pilot study. Nurse Education Today 34(6), 53-57. https://doi.org/10.1016/j.nedt.2013.10.007

[42] Kidd, L. I., Knisley, S. J., \& Morgan, K. I. (2012). Effectiveness of a Second Life Simulation as a Teaching Strategy for Undergraduate Mental Health Nursing Students. Journal of Psychosocial Nursing 50(7), 28 - 37. https://doi.org/10.3928/02793695-20120605-04

[43] Lewett-Jones, T., McCoy, M., Lapkin, S., Noble, D., Hoffman, K., Dempsey, J., Arthus, C., \& Roche, J. (2011). The development and psychometric testing of the Satisfaction with simulation Experience Scale. Nurse Education Today 31(7), 705-710. https://doi.org/10.1016/j.nedt.2011.01.004

[44] Erhel, S., \& Jamet, E. (2013). Digital game-based learning: Impact of instructions and feedback on motivation and learning effectiveness. Computers \& Education 67, 156-167. https://doi.org/10.1016/j.compedu.2013.02.019 
[45] Ketamo, H., \& Suominen, M. (2010). Learning-by-Teaching in Educational Game: Educational Outcome, User Experience and Social Networks. Journal of Interactive Learning Research 21(2), 237-255.

[46] Tsai, F-H., Tsai C-C., \& Lin, K-Y. (2015). The evaluation of different gaming modes and feedback types on game-based formative assessment in an online learning environment. Computers \& Education 81, 259-269. https://doi.org/10.1016/j.compedu.2014.10.013

[47] Goldberg, B., \& Cannon-Bowers, J. (2015). Feedback source modality effects on training outcomes in a serious game: Pedagogical agents make a difference. Computers in Human Behavior 52, 1-11. https://doi.org/10.1016/j.chb.2015.05.008

[48] Fonseca, L., Del' Angelo Aredes, N., Dias, D., Scochi, C., Martins, J., \& Rodrigues, M. (2015). Serious game e-Baby: nursing students' perception on learning about preterm newborn clinical assessment. Revista Brasileira de Enfermagem 68(1), 13-19. https://dx.doi.org/10.1590/00347167.2015680102p

[49] O’Neill, E. S., Dluhy, N. M., \& Chin, E. (2005). Modelling novice clinical reasoning for a computerized decision support system. Journal of Advanced Nursing 49(1), 68-77. https://doi.org/10.1111/j.1365-2648.2004.03265.X

[50] Kuiper, R.A., \& Pesut, D. J. (2004). Promoting cognitive and metacognitive reflective reasoning skills in nursing practice: self-regulated learning theory. Journal of Advanced Nursing 45(4), 381391. https://doi.org/10.1046/j.1365-2648.2003.02921.x

[51] Bulman, C., Lathlean, J., \& Gobbi, M. (2012). The concept of reflection in nursing: Qualitative findings on student and teacher perspectives. Nurse Education Today, 32(5), e8-e13. https://doi.org/10.1016/j.nedt.2011.10.007

[52] Teixeira, C. R. S., Pereira, M. C. A., Kusumoto, L., Gaioso, V. P., Mello, C. L., \& Carvalho, E. C. (2015). Evaluation of nursing students about learning with clinical simulation. Rev Bras Enferm. 68(2), 284-91. https://doi.org/10.1590/0034-7167.2015680218i

[53] Schön, D.A. (1983). The Reflective Practitioner. How Professionals Think in Action. Basic Books.

[54] Kiili, K. (2005). Digital Game-based Learning: Towards an Experiential Gaming Model. The Internet and Higher Education 8(1), 13-24. https://doi.org/10.1016/j.iheduc.2004.12.001

[55] Georg, C., \& Zary, N. (2014). Web-Based Virtual Patients in Nursing Education: Development and Validation of Theory-Anchored Design and Activity Models. Journal of Medical Internet Research 16(4), e105. https://doi.org/10.2196/jmir.2556

[56] Jeffries, P. (2007). Simulation in Nursing Education. From conceptualization to evaluation. National League for Nursing, New York.

[57] Harmon, M., \& Thompson, C. (2015). Clinical reasoning in pre-licensure nursing students. Teaching and Learning in Nursing 10, 63-70. https://doi.org/10.1016/j.teln.2014.12.001

[58] Rigby, S., \& Ryan, R. M. (2011) Glued to games. How video games draw us in and hold us spellbound. Santa Barbara, California: Praeger.

[59] Zhua, D-S., Lin, T., \& Hsua, Y-C. (2012). Using the technology acceptance model to evaluate user attitude and intention of use for online games. Total Quality Management 23(8), 965-980. https://doi.org/10.1080/14783363.2012.704269

[60] Davis, F.D., Bagozzi, R.P., \& Warshaw, P.R. (1989). User Acceptance of Computer Technology: A Comparison of Two Theoretical Models. Management Science 35(8), 982-1003. https://doi.org/10.1287/mnsc.35.8.982

[61] Heinrichs, L R., Youngblood, P., Harter, P., Kusumoto, L., \& Dev, P. (2010). Training Healthcare Personnel for Mass-Casualty Incidents in a Virtual Emergency Department: VED II. Prehospital and Disaster Medicine 25, 424-432. https://doi.org/10.1017/S1049023X00008505

[62] Burns, N., \& Grove, S. K. (2005). The practice of nursing research. Conduct, critique, and utilization. Elsevier Saunders, St. Louis.

[63] Amiel, T., \& Reeves, T.C. (2008). Design-based Research and educational technology: Rethinking technology and the research agenda. Educational Technology \& Society, 11(4), 29-40.

[64] Wang, F., \& Hannafin, M.J. (2005). Design-based research and technology-enhanced learning environments. Educational Technology Research \& Development, 53(4), 5-23. https://doi.org/10.1007/BF02504682. 
Appendix 1.

Subscales and items of the instrument

1. Learning clinical reasoning through gaming

1.1 Learned to collect information

1.2 Learned to process information

1.3 Learned to identify problems/issues

1.4 Learned to establish goals

1.5 Learned to take action

1.6 Learned to evaluate outcomes

2. Authentic patient-related experiences

2.1 Patient scenarios were realistic

2.2 Patient scenarios had enough information

2.3 Patient scenarios were sufficiently challenging

2.4 Patient care felt real

2.5 Patient interaction felt real

3. Active participation in patient care

3.1 I participated actively in patient care

4. Application of nursing knowledge

4.1 Game combines theory and practice

4.2 I applied theoretical knowledge while playing

4.3 I applied my previous experience of patient care while playing

\section{Exploration}

5.1 I tested my competence in the game

5.2 I learned by trial and error in the game

5.3 I can make mistakes safely in the game

5.4 I learned by tryouts in the game

\section{Feedback}

6.1 I received immediate feedback on my decisions

6.2 My mistakes were corrected during gameplay

6.3 I received continuous feedback on my performance

6.4 I received feedback after a completed scenario

6.5 I could follow my progress in the game

6.6 If I received immediate feedback it made me consider my decisions

6.7 If I received continuous feedback I could follow my competency development

6.7 If I received feedback after a completed scenario it revealed my competence

\section{Reflection}

7.1 I considered different options in the game

7.2 The game made me consider my decisions

7.3 While playing I considered my own experiences in patient care

7.4 While playing I considered decisions together with other students

7.5 My professionalism evolved by gaming

\section{Collaborative gaming}

8.1 Collaborative gaming was fun

8.2 I learned from my fellow students by collaborative learning

\section{Usability}

9.1 The game is suitable for social services and health care studies

9.2 Studying by playing was fun

9.3 The game is useful for learning clinical reasoning

9.4 Playing increased my interest in learning clinical reasoning

9.5 The game was easy to use

9.6 I knew how to play the game

9.7 The game motivated me to study 